\title{
Integrating local air quality and carbon management at a regional and local governance level: a case study of south west England
}

\author{
S. T. Baldwin ${ }^{1}$, M. Everard ${ }^{2}$, E. T. Hayes ${ }^{1}$, J. W. S. Longhurst ${ }^{1}$ \\ \& J. R. Merefield ${ }^{3}$ \\ ${ }^{I}$ Faculty of Environment and Technology, \\ University of the West of England, UK \\ ${ }^{2}$ Environment Agency, UK \\ ${ }^{3}$ Department of Life Long Learning, University of Exeter, UK
}

\begin{abstract}
This paper examines the relationship between the policy process for local authority management of air quality and local government initiatives and strategies for carbon mitigation. It seeks to explore the policy and process linkages between the sources of carbon emissions and air quality pollutants in order to assess the potential benefits and/or limitations of an integrated approach for their co-management at a local and regional governance level. Local authorities, as environmental regulators, have a significant role in the UK's attempts to tackle the problems associated with climate change. This paper describes the extent to which non-statutory management of carbon emissions is undertaken at a local governance level in south west England and examines the extent to which carbon emissions and local air quality management are integrated and co-managed at local and regional governance levels. Results are presented from a questionnaire survey of local authorities in the south west and selected others from England conducted in 2007 and presents interim conclusions.
\end{abstract}

Keywords: Local Air Quality Management (LAQM), carbon management, local government, local authority. 


\section{Introduction}

To date, the UK has endeavoured to fulfil its international obligations on mitigation of carbon emissions mainly through policies driven and implemented at a national level. Climate change is a global concern; however, it is at a local level where many of the mitigation measures can be implemented. Central government is increasingly recognising the contribution that local government can make towards delivering the UK's carbon reduction targets, such as those outlined in the Kyoto Protocol. Hilary Benn (Secretary of State for Environment, Food and Rural Affaires), speaking at the annual conference of the Local Government Association 2007, asserted this shift in attitude: "Tackling climate change is the greatest challenge of our generation. Local government is not just a partner in this fight. You are one of the leaders of this fight".

Local Authorities are uniquely placed to provide vision and leadership to their local communities, and their wide range of responsibilities and stakeholder contacts means that they must be critical to delivering the UK's Climate Change Programme [1]. This makes integration of carbon management into local environmental management policy a desirable objective [2]. While it is important to build carbon management policies into the full spectrum of local authority duties and responsibilities, integrating carbon management into specific environmental policy frameworks could prove particularly beneficial. The potential benefits of integrated air quality and carbon management policies have been widely discussed and accepted but despite this, the two areas continue to be managed largely in isolation.

\subsection{Benefits of integrated policies}

The commonality of anthropogenic carbon and traditional air pollution sources (i.e. combustion of fossil fuels and agricultural practices) means that integrated management of emissions contributing to climate change and air quality could deliver considerable ancillary benefits, both fiscally and in terms of human/environmental health. The economic benefits of co-management techniques can be seen as two fold: efficient utilisation of available resources; and ancillary benefits for regional air pollution ensuing reductions in carbon emissions (where driven by demand reduction methods for energy, goods, services etc.). The Stern Review of the Economics of Climate Change addressed the economic benefits of co-management stating, "Policies to meet air pollution and climate change goals are not always comparable. But if government wishes to meet both objectives together, there can be considerable cost savings compared to pursuing them separately" [3]. Moreover, several studies have indicated that a considerable shared investment in climate change policies in Europe could be partially recovered by resultant lower costs in air pollution control of between $20-30 \%$ [4-6].

Through the Local Air Quality Management (LAQM) process, local authorities are required to periodically review and assess traditional local air pollutants, predominantly arising from transport, industry and domestic sources. 
These are similar sources to those of carbon emissions at a local level [2]. On the basis of this observation, it is hypothesised that integrating climate change strategies into aspects of the LAQM process will contribute substantially to local authority-driven reductions in carbon emissions.

\subsection{Local authority climate change initiatives in the UK}

A comprehensive and statutory framework for local government management of carbon emissions has yet to emerge from the policy rhetoric. Despite this there are numerous voluntary declarations, initiatives, and guidance documents available to local authorities in the UK to enable locally-driven carbon reduction.

The most widespread of these initiatives is the Nottingham Declaration on Climate Change. The first of its kind in the UK, the Nottingham Declaration, is a local authority initiative signed by 329 local government bodies to date (approximately $70 \%$ ) which acts as a public statement for local governments to take action to tackle climate change issues at a local level. Local authorities signing the declaration commit to three broad aims; acknowledging that climate change is occurring, welcoming and engaging with the government targets and committing to working at a local level on carbon management [7].

The popular uptake of this initiative has established it as the first step for local governments that want to display their commitment to action. However there is little evidence to suggest that the declaration has resulted in any tangible reductions of carbon emissions at a local level. This may be due to the permissive nature of the declaration which, as a non-statutory initiative, presents no mandatory targets or performance indicators and lacks any sanctions if a council fails to deliver on a particular aspect of the declaration.

The International Council for Local Environmental Initiatives' Cities for Climate Protection (CCP) [8] campaign shares a common objective with the Nottingham Declaration on Climate Change: local government action on climate change and carbon abatement. However, only 49 English local government bodies have joined the CCP to date (approximately 10\%), the majority (43) of which are also Nottingham Declaration signatories. The CCP campaign commits participants to undertaking five milestones: conducting a baseline emissions inventory; adopting a local reduction target; developing a local action plan; implementation of emission reduction policies; and monitoring progress of measures to reduce greenhouse gas emissions. The comparatively small participation in CCP may simply be due to a lack of awareness about the campaign. However, it is also probable that this underlines unwillingness among local authorities to commit to a more resource demanding programme.

\subsection{Local Air Quality Management (LAQM) and carbon abatement}

The current system for air quality management in the UK was legislated through the Environment Act 1995 [9]. This required the publication of the first National Air Quality Strategy, which introduced statutory requirements for local authorities in relation to the assessment and control of air quality. Local authorities are required to periodically review air quality in their area for specific 
pollutants and to assess current and projected future levels of air quality [9]. These reviews are assessed against a number of national Air Quality Objectives (AQOs). Where an area exceeds, or is likely to exceed these AQOs by a stated date, local authorities are required to designate an Air Quality Management Area (AQMA) and develop an Air Quality Action Plan (AQAP) outlining measures they will take to work towards remediating the problem [10]. The application of this process requires many of the same methods, skills and collaborative networks that would be required for an effective carbon management framework at the local level; the production of a robust emissions inventory, embedding carbon in the local and regional Air Quality Strategies, collaborative networks between key stakeholder influencing atmospheric emissions, and joint carbon/air quality action plans. This paper will investigate the opportunities and barriers for local authorities to co-manage carbon emissions at a local level through existing air quality management processes.

\section{Methodology}

The results presented in this paper are taken from a questionnaire survey conducted in 2007 of local government bodies in south west England, and a reference set of English authorities. The survey (a component of an ongoing longitudinal study) was designed to investigate the extent to which traditional air pollutants and carbon emissions are being co-managed at a local governance level in the south west region of England. In England, local government functions are delivered either entirely through a unitary authority, or are split over two tiers: district authorities, and County Councils. In order to investigate the convergence of what are at present considered two separate and parallel policy areas, it is recognised that they are currently managed by three key stakeholders within the various structures of local government:

- Environmental Health Officers (EHOs) responsible for LAQM in a district or unitary council

- Officers dealing with carbon management in a district or unitary council

- Officers dealing with carbon management in a County Council

A selection of local authorities from outside the south west were invited to participate as 'reference' authorities based on their proactive engagement with a combination of voluntary local authority climate change initiatives. The initiatives used as the selection criteria were the Nottingham Declaration on Climate Change [7], the Carbon Trust's Local Authority Carbon Management Program [11], Cities for Climate Protection [8], Sustainable Energy Beacon Councils [12] and Delivering Clean Air Beacon Councils [13]. All local governments participating in these schemes were entered into a database in Microsoft Excel and were selected using a pivot table based on the engagement with at least 3 of the target initiatives. Questionnaires consisted predominantly of closed questions to allow statistical analysis. Where opinions were required, Likert Scale questions were used. All data obtained was analysed using SPSS for Windows. 


\section{Research findings}

Results are presented from 20 South West local authority EHOs and 11 officers with responsibility for carbon management, referred to as Climate Change Officers. 12 local authority EHOs and 10 Climate Change Officers from the reference survey group are also included. Results are presented for four thematic areas identified as import indicators of policy convergence: communication, action plans, emissions inventories and strategies.

\subsection{Communication}

Due to the multiplicity of sources for both air pollution and carbon emission at a local level, the success of control mechanisms relies on inter-profession communication between a numbers of stakeholders. One of the most successful ways of achieving participation between internal departments in local authorities and between external stakeholders is through the formation of multi-disciplinary groups, often referred to as steering groups [14]. These steering groups could include local authority officers across different departments (and in some circumstances neighbouring authorities) and often requires the support of outside bodies, businesses and local community groups. The percentage of EHOs (dealing with air quality) that are involved in an internal and/or external steering group for inter-professional communication on LAQM is shown in Table 1. Data are also provided for the responding local authority Climate Change Officers. In order for local authorities to maximise their impact on local carbon emissions beyond emissions arising from their own operations (vehicle fleet, procurement policy, estate, street lighting etc), it is necessary for steering groups to involve external stakeholders from the wider community. The importance of this has clearly been recognised by the 'reference' authorities of whom $70 \%$ have established such a group. However, while $83 \%$ of south west Climate Change Officer respondents reported establishing an internal steering group for climate change issues; just $27 \%$ had established an external steering group. By contrast, the importance of collaborating with external stakeholders, due to the multiplicity of sources of atmospheric emissions at a local level, became apparent soon after the implementation of the LAQM process. Indeed, $65 \%$ of south west respondents have established such a group, containing many of the relevant stakeholders to local carbon emissions.

Because of the integrated nature of air quality management, the creation of a strong collaborative working relationship between EHOs responsible for LAQM and other stakeholders is imperative to the success of the process. Carbon management at a local level will also necessitate collaboration between key stakeholders with influence or control over climate-active emissions. This will involve many of the same factions as those with influence on air pollution (e.g. local transport professionals, land-use planners, economic development officers, sustainability officers and business/commerce as well as EHOs) [15]. Thus, joint steering groups could have considerable benefits in terms of resource efficiency due to many of the networks and steering groups, established by local authorities 
Table 1: Percentage of local authority respondents involved in internal/external steering groups for $\mathrm{AQ} /$ carbon management and percentage of relevant LA functions in attendance.

\begin{tabular}{|l|c|c|c|c|}
\hline & \multicolumn{2}{|c|}{ EHO } & \multicolumn{2}{c|}{ Climate Change Officer } \\
\cline { 2 - 5 } & South West & English & South West & English \\
\hline $\begin{array}{l}\text { Internal steering group for LAQM/ } \\
\text { Carbon management }\end{array}$ & $10 \%$ & $54 \%$ & $83 \%$ & $100 \%$ \\
\hline $\begin{array}{l}\text { External steering group for LAQM/ } \\
\text { Carbon management }\end{array}$ & $65 \%$ & $38 \%$ & $27 \%$ & $70 \%$ \\
\hline
\end{tabular}

to assist them in their air quality duties, being intrinsically representative of those with influence on carbon emissions at a local level.

\subsection{Air Quality Action Plans}

Air Quality Action Plans (AQAPs) are the mechanisms by which local authorities identify the measures they will implement to work toward meeting the AQOs. However, actions taken to improve local air quality can result in synergistic or trade-off outcomes for greenhouse gas emissions and vice versa. Therefore, it is important that AQAPs are developed with non-air quality impacts such as the potential effect on GHGs emissions taken into account. Table 2 describes the percentage of south west local authority respondents that considered non air quality issues in the development of their action plan and the level of priority assigned to carbon mitigation measures. Of the respondents that have an active AQAP, only $27 \%$ of south west respondents considered issues other than air quality in their action plan, compared to $57 \%$ of the corresponding reference authorities. However, the mean score assigned to the level of priority carbon mitigation is given is low for both survey groups suggesting that in AQAPs, adequate attention is not been given to the impact measures may have on local carbon emissions.

Table 2: $\quad$ Percentage of local authority respondents that have an AQAP and the level of priority assigned to non air quality issues.

\begin{tabular}{|l|l|l|}
\hline \multirow{2}{*}{ Current Air Quality Action Plan } & \multicolumn{2}{|c|}{ EHO } \\
\cline { 2 - 3 } & South West & English \\
\hline AQAP considering non AQ issues & $55 \%$ & $54 \%$ \\
\hline Priority of carbon mitigation in AQAP (mean) & $27 \%$ & $57 \%$ \\
\hline Priority of climate change adaptation in AQAP (mean) & 1.82 & 1.43 \\
\hline
\end{tabular}

(scale: $1-6,1=$ low $6=$ high)

There is a significant opportunity for a combined air quality and carbon management action plan where synergistic outcomes are given priority over those actions that may result in a trade-off situation, i.e. where an action taken to reduce traditional air pollutants result in an increase of carbon emissions or vice versa. 


\subsection{Emissions inventories}

Emissions inventories are well established in the LAQM process and are important for establishing baseline data, however, if used effectively, local authorities could utilise their existing skills to produce combined air pollution and carbon emission inventory for the purpose of integrated planning, actions planning and strategies [16]. Table 3, shows the percentage of EHO and Climate Change Officer respondents that have produced an emissions inventory for LAQM pollutants and $\mathrm{CO}_{2}$ emissions respectively for their local authority operations and their administrative area. The table also describes the percentage of those local authority respondents that have produced a combined emissions inventory for LAQM pollutants and $\mathrm{CO}_{2}$ emissions. The importance of an emission inventory for carbon emissions is highlighted by the contrast between south west respondents (36\%) and the 'reference' authority respondents $(80 \%)$ who have produced an inventory for $\mathrm{CO}_{2}$ emissions arising from their own operations. In order for local authorities to maximise the impact they have on locally-driven carbon emissions, it would also require them to tackle emission from sources outside of their direct influence. The results show that a comparatively small percentage of respondents have produced an emissions inventory for their administrative area for both LAQM pollutants ( $26 \%$ and $46 \%$ of south west and 'reference' authority respondents respectively) and carbon emissions $(27 \%$ and $40 \%$ of south west and 'reference' authority respondents respectively).

Table 3: Percentage of local authority respondents that have conducted an emissions inventory of LAQM pollutants/ $\mathrm{CO}_{2}$ for their own operations and/or their administrative area.

\begin{tabular}{|l|l|l|l|l|}
\hline & \multicolumn{2}{|c|}{ EHO } & \multicolumn{2}{c|}{$\begin{array}{c}\text { Climate Change } \\
\text { Officer }\end{array}$} \\
\cline { 2 - 5 } & South West & English & South West & English \\
\hline Conducted an emission inventory of $\mathrm{LAs} \mathrm{CO}_{2}$ & - & - & $36 \%$ & $80 \%$ \\
\hline $\begin{array}{l}\text { Conducted an emission inventory of } \mathrm{LAQM} \\
\text { pollutants } / \mathrm{CO}_{2} \text { in administrative area }\end{array}$ & $26 \%$ & $46 \%$ & $27 \%$ & $40 \%$ \\
\hline $\begin{array}{l}\mathrm{CO} \\
\text { inventory }\end{array}$ & $40 \%$ & $33 \%$ & - & - \\
\hline
\end{tabular}

The technical and non-technical skills displayed by local authorities producing emissions inventories for LAQM purposes would therefore lend themselves to the production of emission inventories for a basket of atmospheric emissions encompassing both 'traditional' air pollutants and carbon emissions. Utilising the existing skill set in this area could therefore be an effective and efficient use of local authority resources in managing carbon emissions, reducing the need for capacitybuilding associated with implementing new auditing and management processes.

\subsection{Local air quality and climate change strategies (LAQS and CCS)}

When undertaking an LAQS a steering group is usually established representing some of the key stakeholders with responsibility or control over emissions to the 
atmosphere. Currently, the majority of CCS at a local level are being developed separately from their air quality counterpart. A combined LAQS and CCS could bring all relevant stakeholders together and ensure the two areas are prioritised effectively at a local and regional level. The percentage of south west local authority respondents that have produced a LAQS and CCS and the level of priority that carbon management is given in LAQS is show in Table 4. Despite the benefits of a LAQS, only $37 \%$ of south west local authority respondents have produced one. However, more that half $(55 \%)$ of the south west respondents have produced a CCS. This is probably accounted for by the fact the LAQM review and assessment process is prescriptive and cyclical in nature, thus, reducing the need for a voluntary LAQS. A prescriptive and uniform process for the management of carbon emissions at a local level does not yet exist, making CCSs a useful strategic tool. It could also be argued that climate change has become a more prevalent issue than air quality in public opinion, leading to CCS being used as a public relations tool.

Table 4: $\quad$ Percentage of local authority respondents that have produced a LAQS and/or CCS and the level of priority given to carbon in LAQS.

\begin{tabular}{|l|c|c|c|c|}
\hline \multirow{2}{*}{} & \multicolumn{3}{|c|}{ EHO } & \multicolumn{3}{c|}{ Climate Change Officer } \\
\cline { 2 - 5 } & South West & English & South West & English \\
\hline Produced a LAQS/CCS & $37 \%$ & $39 \%$ & $55 \%$ & $60 \%$ \\
\hline Usefulness of LAQS for LAQM & 2.59 & 3.80 & - & - \\
\hline Priority of carbon mitigation in LAQS & 1.86 & 1.80 & - & - \\
\hline Priority of carbon adaptation in LAQS & 2.29 & 1.80 & - & - \\
\hline
\end{tabular}

(scale: $1-6,1=$ low $6=$ high)

\subsection{Additional observations}

It is apparent from the results presented that local authorities face a number of barriers to achieving an integrated system for the co-management of air quality and carbon emissions. The LAQM process is now well established, with all local authority respondents employing an officer with primary responsibility for air quality. Conversely, only $20 \%$ of south west local authority respondents employ an office with primary responsibility for carbon management, compared to $78 \%$ of the 'reference' authorities from outside the south west. This seemingly large disparity between the two groups is due to the lack of ability, or willingness, to allocate scarce resources to an issue that is not yet a statutory responsibility. Those respondents that, as yet, had not produced a CCS were asked to rank a compendium of reasons why they had chosen not do so. The highest scoring reason given was 'not a statutory requirement' followed by 'other issues having higher priority' and 'lack of time'. This suggests that a strong statutory framework is required to drive management of carbon emissions at a local level and necessitate the allocation of time and resources. Integration of carbon emissions into the LAQM framework could prove an efficient use of these 
resources. When the LAQM process was introduced, many local authorities express concern that they did not have the technical skills or capacity to fulfil their statutory duties. In response to this Defra and the Devolved Administrations (Scotland, Wales and Northern Ireland) established a range of LAQM guidance documents and helpdesks to assist local authorities in their needs. In general local authorities seem happy with the level of guidance they now receive, with the south west respondents rating the LAQM guidance documents as 'very useful'. However, the same group strongly agreed with the statement 'There is a need for more prescriptive guidance in the policy and technical guidance documents for carbon management within LAQM', expressing the need for more comprehensive guidance incorporating carbon emissions.

\section{Conclusion}

The absence of a statutory requirement for carbon management was consistently reported by south west local authorities as being the main reason for inaction. This statutory requirement seems critical to facilitate the necessary allocation of time and resource. It is apparent from the results presented that despite the increased attention carbon management receives at an international and national level, it has yet to be effectively and comprehensively embedded at a local government level. While many local authorities now recognise the influence they can have on carbon emissions in their respective areas, and are proactively seeking to engage with initiatives for carbon management, there is only limited integration between the LAQM process and local government's management of carbon emissions. Reducing emissions of carbon and minimising the likely impact of future developments and lifestyles needs to come from a range of local functions such land use planning, building control, transport planning and waste management. However, the LAQM process is unique as the only local function that links these areas together. LAQM is a process designed to review, assess and manage certain atmospheric emissions. Therefore it provided many of the technical skill required to review and assess locally derived carbon emissions and already engages many of the relevant stakeholders.

\section{References}

[1] Department for Environment, Food and Rural Affairs, Climate Change: the UK Programme. The Stationary Office: London, 2006.

[2] Hayes, E.T., Chatterton, T.J., Leksmono, N.S. and Longhurst, J.W.S., Integrating climate change management into the local air quality management process at a local and regional governance level. Proc. of the $14^{\text {th }}$ Int. Conf. On Modelling, Monitoring and Management of Air Pollution, eds. J.W.S. Longhurst \& C.A. Brebbia, WIT Press: Southampton, pp. 439-446, 2006.

[3] Stern, N., The Economics of Climate Change, Cambridge University Press: Cambridge, UK, 2007. 
[4] Alternative Policy Study for Europe and Central Asia; United Nations Environment Programme, Global Environment Outlook 2000, Online. http://www-cger.nies.go.jp/geo2000/english/text/0229.htm

[5] RIVM, EFTEC, NTUA and ILASA, European Environmental Priorities: An Integrated Economic and Environmental Assessment. National Institute of Public Health and the Environment: Bilthoven, 2001.

[6] Van Harmelen, T., Bakker, J., de Vries, B., van Vuuren, D.P., den Elzen, M.G.J., Mayerhofen, P., An analysis of the costs and benefits of joint policies to mitigate climate change and regional air pollution in Europe. Environmental Science and Policy 5 (4), pp. 349-365, 2002.

[7] Nottingham Declaration on Climate Change; Energy Savings Trust, Online. http://www.energysavingtrust.org.uk/housingbuildings/localauthorities/Nott inghamDeclaration

[8] Cities for Climate Protection; International Council for Local Environmental Initiatives, Online. http://www.iclei.org/index.php?id=800

[9] HM Government, Environment Act 1995. The Stationary Office: London, 1995.

[10] Longhurst, J.W.S., Beattie, C.I., Chatterton, T.J., Hayes, E.T., Leksmono, N.S., and Woodfield, N.K., Local air quality management as a risk management process: assessing, managing and remediating the risk of exceeding an air quality objective in Great Britain. Environment International 32, pp. 934-947, 2006.

[11] Local Authority Carbon Management Programme; Carbon Trust, Online. http://www.carbontrust.co.uk/carbon/ public sector/la/

[12] Sustainable Energy Beacon Councils; Improvement and Development Agency, Online. http://www.beacons.idea.gov.uk/

[13] Delivering Clean Air Beacon Councils; Improvement and Development Agency. http://www.beacons.idea.gov.uk/

[14] Beattie, C.I. \& Longhurst, J.W.S., Joint Working within Local Government: air quality as a case study. Local Environment 5, pp. 401414, 2002.

[15] Beattie, C.I., Longhurst, J.W.S., and Woodfield, N.K., Air Quality Action Plans: early indicators of urban local authority practice in England. Environmental Science \& Policy 5, pp. 463-470, 2002.

[16] Hayes, E.T., Leksmono, N.S., Chatterton, T.J., Symons, J.K., Baldwin, S.T., and Longhurst, J.W.S., Co-management of carbon dioxide and local air quality pollutants: identifying the 'win-win' actions. Proc. Of the $14^{\text {th }}$ IUAPPA World Congress, Brisbane, Australia, 2007. 